\title{
IMPRENSA E CONTRA-HEGEMONIA NA AMAZÔNIA: o caso do Jornal Pessoal
}

\author{
Press and counter-begemony in Amaron: \\ the case of Jornal Pessoal
}

\author{
Maria do Socorro Furtado Veloso \\ Jornalista, professora adjunta do Departamento de Comunicação Social da Universidade Federal do Rio Grande do Norte \\ (UFRGN), Natal, RN - Brasil, e-mail: socorroveloso@uol.com.br
}

\begin{abstract}
Resumo
A reconstituição da história do Jornal Pessoal é o objetivo central deste artigo. Considerado a mais importante e longeva experiência alternativa do jornalismo amazônico, o periódico é conduzido solitariamente pelo jornalista Lúcio Flávio Pinto. Criado em 1987, em Belém (PA), representa um modelo de imprensa contra-hegemônica no Brasil da pós-ditadura. Tem na ausência de publicidade uma de suas principais características. A linha editorial é inspirada no I.F Stone’s Weekly, um semanário produzido durante 19 anos nos EUA, pelo jornalista Isidore Stone. Este estudo visa discutir as razões da existência e longevidade do Jornal Pessoal, que sobrevive a despeito de uma intensa campanha de processos na Justiça. Também pretende demonstrar de que forma seu editor consolida, por meio do jornal, a função de intelectual público, a qual incorporou depois de exercer o jornalismo diário por 21 anos. A história do JP, seus campos de interesse, e suas preocupações quanto aos fundamentos e ao exercício da profissão, são os eixos de investigação do estudo, que utiliza como procedimentos metodológicos a pesquisa documental e bibliográfica, entrevista e análise de conteúdo.
\end{abstract}

Palavras-chave: Jornal pessoal. Jornalismo alternativo. Imprensa amazônica.

\begin{abstract}
The history reconstitution of Jornal Pessoal is the main goal of this paper. Considered as the most important and lasting experience of alternative journalism in Amazon, the newspaper is for the journalist Lúcio Flávio Pinto lonely. Created in 1987, in Belém (PA), it represents a model of counter-hegemonic press in Brazil, in the post dictatorship period. The Jornal Pessoal has the absence of advertising as one of its most important characteristics. Its editorial guideline is inspired in the I.F Stone's Weekly, self-published for 19 years in U.S.A, by the journalist Isidore Stone. This study intends to discuss the reasons of the existence and lasting of Jornal
\end{abstract}


Pessoal, which survives in spite of an intense campaign against it, in the court. The study also tries to demonstrate how its editor consolidates, by the newspaper, a function of public intellectual, which he incorporated after work in daily journalism for 21 years. The JP's history, its interests fields, and his concerns about the foundations and practice of journalism are the axes of this investigation, that uses documental and bibliographic research, interview and content analyses as methodological procedures.

Keywords: Jornal pessoal. Alternative journalism. Amazonian press.

\section{INTRODUÇÃO}

Em 2003, quando esteve no Brasil como palestrante do XXVI Congresso da Intercom, o pesquisador britânico John D.H. Downing manifestou incômodo com a profusão de pesquisas em comunicação voltadas aos meios hegemônicos, em detrimento das formas alternativas de expressão. Chamou atenção para as iniciativas que, no âmbito da mídia, expressam "uma visão alternativa às políticas, prioridades e perspectivas hegemônicas" (ASSIS, 2003).

Autor de Mídia radical, Downing (2002) é especialmente preocupado comveículos deinformação que são produzidos com parcos recursos e algumas vezes têm pouco reconhecimento da comunidade: "de tempo em tempo [esses veículos] tornam-se alvo da raiva, do medo ou do ridículo de alguma autoridade, ou mesmo do público em geral, ou ambos. Às vezes têm vida curta [...]; outras, perduram por muitas décadas" (DOWNING, 2002, p. 29).

A proposta deste artigo é analisar a história do Jornal Pessoal, que aqui também será chamado de JP, além de indicar questões para refletir sobre o problema. Utilizamos como procedimentos metodológicos a pesquisa bibliográfica e documental, entrevistas e análise de conteúdo.

O Jornal Pessoal é um quinzenário conduzido solitariamente pelo jornalista paraense Lúcio Flávio Pinto. Criado em 1987, em Belém do Pará, chegou à $440^{a}$ edição em maio de 2009 . O veículo tem longevidade superior à média dos periódicos alternativos no Brasil, tomando-se por base o estudo de Bernardo Kucinski, Jornalistas e revolucionários (1991).

Editado em formato A-4 (ofício), em papel linha d'água, tem 12 páginas e calcula-se que seus dois mil exemplares sejam lidos por $12 \mathrm{mil}$ pessoas, em média. Seu editor investe prioritariamente em pautas voltadas para a política regional, economia e meio ambiente - com ênfase no impacto dos grandes projetos desenvolvidos na Amazônia por empresas privadas e estatais -, narcotráfico, mídia, escândalos financeiros e problemas urbanos. A ausência de anúncios publicitários é uma das singularidades do periódico, que se mantém apenas com a venda em bancas. $\mathrm{O}$ exemplar custa $\mathrm{R} \$ 3,00$.

Graduado em Sociologia e considerado um dos maiores especialistas brasileiros em problemas amazônicos, Lúcio Flávio Pinto trabalhou para as revistas Veja e Realidade, e cobriu a região para o jornal O Estado de S. Paulo por 17 anos. Decidiu afastar-se da grande imprensa em 1988, um ano após a criação do JP, para se dedicar ao alternativo.

O Jornal Pessoal foi criado com base em experiência similar desenvolvida entre 1952 e 1971, nos Estados Unidos, pelo jornalista Isidore Feldenstein Stone, que saiu do New York Times para fundar o I.F. Stone's Weekly - inicialmente um pequeno semanário, depois quinzenário alternativo, cuja tiragem máxima atingiu 30 mil exemplares.

Vivendo em realidades tão distintas (Belém e Washington), Lúcio Flávio e Isidore Stone partiram da mesma - e incômoda constatação para abrir o próprio jornal: eles não encontravam nas bancas aquelas que consideravam as notícias mais importantes do dia. "O grande elo entre os dois [Jornal Pessoal e I.F. Stone's Weekly] está em demonstrar que a utopia é possível, se você está disposto a pagar o preço”, comenta Lúcio Flávio.

Ao propor um campo independente de interpretação da realidade amazônica independência que se ampara, sobretudo, na recusa à publicidade e na condução solitária do jornal -, o

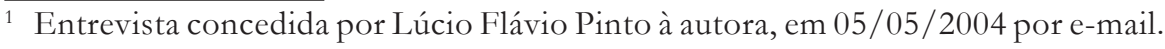


JP evidencia a precariedade do conteúdo fornecido pelas mídias noticiosas dominantes no Norte do Brasil. Por essa razão, aliada à consciência de que a memória é um dos pilares dos processos culturais, Lúcio tem feito do Jornal Pessoal uma espécie de "cimento" da história contemporânea da região.

Na construção dessa memória, o JP trabalha primordialmente com análises - textos de caráter argumentativo e/ou especulativo, necessariamente decorrentes de fatos ocorridos ou previstos. Mesmo nos textos mais curtos do alternativo o tom é de suelto: aquilo que se informa é sempre objeto de comentário, em geral espirituoso ou irônico. O jornalista admite não produzir reportagens ou notícias no JP:

O Jornal Pessoal é uma agenda amazônica. Ele quer entrar na agenda dos cidadãos, quer fornecer informação útil. Não adianta minha informação estar num belo trabalho acadêmico, se não está disponivel aos agentes sociais, aos personagens, aos atores, ao príncipe da história. O Jornal Pessoal é sempre analítico. Mas analítico com base nos fatos, nas informações. A minha trajetória no jornalismo é exemplar no sentido de que eu sempre fui um escravo dos fatos. [...] As matérias do Jornal Pessoal não são notícias, não são reportagens, não são artigos. São análises. Elas são uma auditagem dosfatos. Eu, como jornalista, sou auditor do povo. E não existe, na estrutura institucional da nossa sociedade democrática, auditagem mais popular que a do jornalista. ${ }^{2}$

A publicação de Lúcio Flávio Pinto opera como contraponto à agenda imposta pela mídia hegemônica paraense, à medida que divulga e/ou interpreta informações que, submetidas à interdição do dizer (ORLANDI, 1995), de outra forma não circulariam. Essa interdição pode ocorrer porcensura, autocensura, omissão, ou mesmo manipulação.

\section{Imprensa e contra-hegemonia}

Um dos pressupostos para a compreensão do ambiente em que opera o Jornal Pessoal é a questão da hegemonia, pensada a partir de O'Sullivan (2001), com base em Gramsci. No modelo capitalista, a mídia aparece ao lado da escola, da lei, do Estado e da família como um espaço privilegiado para o exercício da liderança pelas classes dominantes, visando à manutenção do poder econômico, político e cultural sobre o conjunto da sociedade. $\mathrm{O}$ aspecto fundamental dessa noção é a necessidade que as alianças hegemônicas tem de buscar "ativamente o consentimento geral para os modos de fazer sentido no mundo" (O'SULLIVAN, 2001, p. 121-122), sem que para isso abdiquem da coerção direta sobre as classes dominadas.

Produzidos a partir das instituições "colonizadas" por um determinado bloco de poder, os conhecimentos, sensos e sentidos "são organizados e interpretados de tal modo que transformam os interesses do 'bloco' dominante em [...] aparentemente naturais, inevitáveis, eternos, e, portanto, indiscutíveis" (O'SULLIVAN, 2001, p. 122). De acordo com esta concepção, o bloco de poder abriga não apenas a classe que exerce a autoridade cultural, política e econômica, mas também segmentos da classe subordinada que entendem seus interesses como os mesmos do grupo dominante. Como resume O'Sullivan (2001, p. 122), "a hegemonia naturaliza o que historicamente representa uma ideologia de classe, tornando-a uma forma de senso comum."

As contradições inerentes ao modelo capitalista, que se manifestam nos conflitos de interesse gerados pelas formas de propriedade e pelo modo de produção, no entanto, impedem a subordinação absoluta de uma classe social a outra. A hegemonia não é total. "Sempre há formas emergentes de consciência e representação podendo ser mobilizadas em oposição à ordem" vigente ( $\mathrm{O}^{\prime}$ SULLIVAN, 2001, p. 122). Neste contexto, aparecem as estratégias alternativas, que se apresentam no campo do confronto e tomam por base a consciência contra-hegemônica. Ao bloco de poder cabe desabilitá-las de sentido, dando a essas estratégias a condição de "não oficiais".

Os meios de comunicação, historicamente, são um espaço de resistência das formas contra-hegemônicas aos grupos dominantes (LINS DA SILVA, 1982). Essa resistência pode ser pensada a partir do modelo de contrainformação de Pio Baldelli (1972): trata-se da tentativa de "garantir a circulação de informações sobre situações de classe, à margem dos canais controlados pelo poder constituído e também utilizando os espaços que as contradições da burguesia oferecem no seio desses canais" (BALDELLI, 1972, apud FADUL, 1982, p. 36).

\footnotetext{
$\overline{2}$ Entrevista concedida por Lúcio Flávio Pinto à autora em 18/07/2005 (gravada).
} 
Ao constatar a eficiência dos meios de comunicação de massa na manutenção da hegemonia burguesa, cujas operações visando à preservação desse controle são muitas vezes ignoradas pelas classes subalternas, Lins da Silva (1982, p. 17-21) afirma que uma das tarefas primárias da contrainformação é a denúncia dessas operações. Já Fadul (1982, p. 36) acrescenta que essa prática embute "tanto a operação clandestina, fora do circuito normal, com a criação de meios populares próprios de transmissão de informações, como a ocupação de espaços e brechas deixados pelos meios de comunicação [...]."

No Informe Mc Bride, produzido no início dos anos 1980 pela Comissão Internacional para o Estudo dos Problemas da Comunicação, a contrainformação é também chamada de "comunicação de substituição". A força dessa comunicação produzida por grupos dissidentes, diz o relatório, está nas relações interpessoais, nas quais obtém algum poder para desafiar a autoridade ou contornar entraves. Pelo conteúdo, regularidade e número de pessoas que atingem, os veículos mantidos por esses grupos não podem ter como finalidade concorrer com os meios massivos. No entanto, observa o documento, "o repúdio radical da corrente radical dominante, o fortalecimento da coesão de certos grupos e a capacidade que oferece para o desenvolvimento das redes horizontais dão-lhe uma importância que não se mede pelas cifras que servem de medida comum" (MC BRIDE, 1983, p. 285).

Silenciar a voz dos dissidentes é colocar em xeque a credibilidade dos órgãos de informação na sua totalidade:

Impondo silêncio à controvérsia, o Estadoparece temê-la [...]. Além disso, o controle dos meios de comunicação é solapado por outros métodos de comunicação: as notícias repetidas de boca em boca e os escritos clandestinos que, mesmo rudimentares, fazem surtir os seus efeitos, pois a repressão de que padecem serve para aumentar sua credibilidade (MC BRIDE, 1983, p. 32).

Fontcuberta e Mompart (1983), no entanto, defendem a necessidade de estabelecer diferenças entre informação clandestina, presente nos regimes totalitários, e contrainformação. Esta, dizem os autores, parte da constatação de que a informação dominante - seja a oficial, a dos grupos políticos majoritários ou de centros de poder importantes "oculta, deforma ou falseia os fatos". Com isso, procura trazer à luz a "mentira, dando outra versão dos acontecimentos e apresentando dados sobre os quais a informação original havia silenciado" (FONTCUBERTA; MOMPART, 1983, p. 102).

Perspectiva similar oferece Marcondes Filho, que usa o termo "contracomunicação" para nomear o fornecimento de informações de natureza distinta, às vezes oposta às informações dos grandes veículos estabelecidos de comunicação, e proporcionar uma outra interpretação dos fenômenos políticos e sociais, voltada mais para os interesses dos grupos dominados da sociedade (LINS DA SILVA, 1982, p. 59). Guardadas as especificidades históricas, essa categorização se aproxima da experiência do Jornal Pessoal.

O campo da comunicação de massa no Pará é dominado, hoje, por dois grandes grupos: as Organizações Romulo Maiorana (ORM), pertencentes à família Maiorana, e a RBA (Rede Brasil Amazônia), do ex-governador, ex-ministro e atual deputado federal Jader Barbalho (PMDB). Ambos detêm, respectivamente, a concessão dos principais canais de TV do Estado: TV Liberal (Canal 7), retransmissora da TV Globo e líder de audiência local; e a TV RBA (Canal13), retransmissora da Bandeirantes. Também são donos de dois dos maiores jornais impressos da região Norte: O Liberal, dos Maiorana, e o Diário do Pará, dos Barbalho.

O grupo RBA detém três emissoras de rádio na capital - Clube AM, Diário FM e 99 FM - e cinco no interior do Estado, enquanto as ORM são proprietárias de um segundo jornal impresso diário, o Amazônia, uma emissora de TV a cabo, duas emissoras de rádio na capital - Liberal AM e Liberal FM - e quatro no interior, um portal de internet, além de oito emissoras de TV no interior.

A indústria midiática paraense reitera as formas de funcionamento da indústria cultural brasileira, caracterizada pela presença dominante de grupos familiares e pela aliança com as elites de poder locais (LIMA, 2001). Esses grupos estão à frente de alguns dos principais conglomerados de comunicação no Brasil, como é o caso da Rede Globo (família Marinho), SBT (Abravanel) e Bandeirantes (Saad), e se consolidaram por meio da propriedade cruzada na radiodifusão (rádio e televisão) e/ou na mídia impressa (jornais e revistas). Neste cenário destacamse também as famílias Civita (Abril), Frias (Folha de S. Paulo) e Mesquita (O Estado de S. Paulo).

Mantidos por oligarquias empresariais e políticas, os veículos de comunicação regionais sofisticaram-se na forma, mas se mantêm 
conservadores na concepção do conteúdo. Neles predomina a visão hegemônica, que superficializa os acontecimentos, submetendo-os ao chamado "pensamento único", em contraponto a um mundo cada vez mais complexo e plural. Na perspectiva de Adorno (1975, p. 289), a velocidade das mudanças dissimula a ausência de transformação, ou seja:

O que na indústria cultural se apresenta como um progresso, oinsistentemente novo que ela oferece, permanece, em todos os seus ramos, a mudança de indumentária de um sempre semelhante; em toda parte a mudança encobre um esqueleto no qual houve tão poucas mudanças como na própria motivação do lucro desde que ela ganhou ascendência sobre a cultura.

A linha editorial dos periódicos locais conduz invariavelmente à conclusão de que os interesses de seus dirigentes são tratados como prioridade absoluta. Esses interesses, obviamente, estão sempre muito distantes do conceito de informação como bem social, ao qual todos podem ter acesso, indiscriminadamente.

É bastante provável que os habitantes de um dos Estados mais pobres da Federação - o que contradiz a presença, em seu território, da maior província mineral do planeta - não se percebam nesta condição ao consumir o conteúdo noticioso produzido pela imprensa da terra. A rigor, o estatuto colonial da Amazônia, tão insistentemente denunciado por Lúcio Flávio Pinto em seu Jornal Pessoal, não está refletido e problematizado na mídia paraense.

Nas páginas dos jornais diários e nos jornalísticos produzidos por emissoras de rádio e TV, esportes, fait divers, colunismo social e vida de celebridades disputam espaço com o material fornecido pelas agências de notícias nacionais e internacionais, cujo valor intrínseco, se não deve ser desmerecido, pouco contribui para a constituição de um senso crítico permanente face às demandas da cultura, da política e da economia regionais.

Essas limitações certamente são fruto das castrações a que as empresas de comunicação estão submetidas em decorrência do modelo altamente concentrador de renda: "a [castração] do anunciante, em primeiro lugar, e a do governo, em segundo, que não é só um dos maiores anunciantes, como dono do poder de aprovar ou cassar as concessões para operações dos canais de rádio e TV em todo o País" (BORIN, 1987, p. 47).
A pluralidade de opiniões, que seria natural e desejável em um ambiente democrático, cede espaço ao que Nelson Werneck Sodré (1999, p. 16) identifica como uma "impressionante uniformidade de posições". Em introdução à edição de 1999 da obra História da imprensa no Brasil, Sodré constatou: “[...] No momento, por exemplo, todos os grandes jornais apoiam o neoliberalismo adotado pelo governo brasileiro, uns com mais veemência, com menos veemência outros."

A histórica associação entre poder político e poder midiático no Pará, e suas consequências, estão registradas nas páginas do JP. Entre 1987 e 2007, 36 das 401 capas do jornal foram dedicadas aos problemas da imprensa no Estado. A montagem e expansão do império de comunicação do atual deputado Jader Barbalho, por exemplo, foi testemunhada desde o nascedouro pelo JP. Na edição n. 55, de janeiro de 1990, sob o título "O novo imperador", Lúcio escreveu:

Em 1983, quando assumiu o governo do Estado, Jader Fontenelle Barbalho dispunha apenas de um pequeno jornal, com tiragem limitada, editado precariamente. Na semana passada, sete anos depois, o ministro da Previdência Social [no governo Sarney] passava a ser dono da segunda maior rede de comunicações do Pará, formada por um jornal modernizado, duas emissoras de rádio e a mais bem instalada estação de televisão. Pornove milhões de dólares, segundo uma fonte bem próxima da transação, ou sete milhões, segundo outras fontes, a TV RBA saiu do controle do grupo Belauto e passou a fazer parte do Sistema Clube do Pará, um título auto-assumido que não esconde a estratégia de competir com o Sistema Romulo Maiorana, detentor do principal império de comunicação do Estado.

[...]

Esses números naturalmente estimulam o leitor mais crédulo a perguntar-se sobre a origem desses fundos. A biografia de Jader Fontenelle Barbalho, confrontada com o patrimônio que formou, gera um estado de perplexidade (PINTO, 1990, p. 1-2).

Quanto ao envolvimento dos jornais nas disputas eleitorais, em julho de 1991 Lúcio observou que os palanques armados no ano anterior, para as eleições estaduais, continuavam de pé no Pará, agora por meio dos jornais. O objetivo, dessa vez, era a campanha para a prefeitura: 
Se essa ameaça de disputa começa a aquecer as páginas até então gélidas dos jornais, pode substituir nelas a informação pela opinião e dirigir o noticiário conforme os interesses em jogo. Nos pontos extremos, em que estão o Sistema Romulo Maiorana de Comunicação e o grupo do governador Jader Barbalho, tratase de uma luta de vida ou morte. Cada um dos antagonistas só admite sobreviver se for à custa do aniquilamento do outro. [...]

O grupo Liberal apostou todas as suas fichas na vitória do candidato do então governador Hélio Gueiros, o ex-prefeito Sahid Xerfan [que foi derrotado por Jader nas eleiçoes estaduais do ano anterior, 1990]. Para transformar-se no principal instrumento de divulgação da chapa oficial, foi presenteado com a mais pesada campanha publicitária que uma empresa jornalística recebeu de um governo do Estado nos últimos anos. "O Liberal" deixou de lado o jornalismo para se tornar um órgão de partido, tão envolvido que demorou até admitir que Jader Barbalho era governador eleito e citá-lo nominalmente no noticiário, do qual foi expurgado - exceto quando era alvo de críticas - nas duas passagens pelo ministério Sarney. $[\ldots .$.

Com o apoio de Orestes Quércia (que lhe arranjou a Editora Bauru, ainda hoje a razão social da firma), Jader criou o precário "Diário do Pará" e melhorou-o graças às extensões de poder que exerceu. O grupo Liberal e ele foram, durante seu primeiro governo, inimigos cordiais ou amigos desconfiados, conforme as variações da conjuntura. Antes da violenta campanha eleitoral do ano passado [em 1990, para o governo do Estado] quebrar todas as aparências de cordialidade, a disputa comercial entre os dois grupos de comunicação, que só podem se expandir colidindo, jogou-os na guerra aberta. Política e negócios passaram a se confundir num nó quase impossível de desfazer. (PINTO, 1991, p. 1-2).

As contendas entre os dois grupos de comunicação foram capa de quatro das 401 edições do JP analisadas neste estudo: $\mathrm{n}^{\circ} 325$, de junho de 2004; 341, de março de 2005; 385, de fevereiro de 2007; e 396, de julho de 2007. O embate começou com a fundação do Diário do Pará, em agosto de 1982, e se intensificou nos 25 anos seguintes. $\mathrm{O}$ artigo principal da edição $\mathrm{n}^{\circ}$ 341 , de fevereiro de 2005, é um dos que melhor expressam a rivalidade político-empresarial entre as famílias Maiorana e Barbalho:
O leitor da edição dominical do dia 27 de fevereiro dos dois principais jornais do Pará teve uma dimensão do que são as elites do Estado. Tanto O Liberal quanto o Diário do Pará dedicaram suas manchetes de capa a denúncias mútuas sobre desvio de recursos públicos para fins ilícitos e associação criminosa, com significativos pontos de contato entre ambas as denúncias.

Sob a manchete "Escândalo da Sudam, 6 anos depois - Todos ricos, todos soltos", O Liberal acrescentou doisitens: ("1 - Até agora, nenhum dos mais de 40 denunciados por desvio de verbas foi parar na cadeia; 2 - Consórcio da morte da irmã Dorothy envolve a máfia de fraudadores da Sudam") e um texto de chamada da matéria: "Apesar de terem sido denunciados pelo Ministério Público Federal, há três anos, pelo desvio de $\mathrm{R} \$ 1,2$ bilhão dos cofres da Sudam, dezenas de políticos, empresários e servidores continuam soltos e prosperam em suas atividades. Entre os envolvidos está o deputado federal Jader Barbalho. Segundo autoridades, o esquema que fraudava a extinta Sudam tem ramificações com o crime organizado na região da Transamazônica".

Já o Diário do Pará apregoou em sua capa: "Hotel fantasma de Maiorana desviou milhões da Sudam". O texto de chamada completava: "O empresário Romulo Maiorana tomou empréstimo de $\mathrm{R} \$ 2,5$ milhões da extinta Sudam para construir um hotel no igarapé Marajá, no município de Novo Airão (AM), a $65 \mathrm{~km}$ de Manaus. Até hoje, oito anos depois, o empreendimento não saiu do papel - nem os recursos foram devolvidos aos cofres públicos.” (PINTO, 2005, p. 1-2).

No artigo, Lúcio Flávio lembra que as denúncias de $O$ Liberal não são novas, mas voltaram a gerar interesse pela associação de alguns beneficiários de fraudes na Sudam, a Superintendência do Desenvolvimento da Amazônia, com madeireiros e fazendeiros acusados de patrocinar a morte da freira Dorothy Stang, em fevereiro de 2005. No caso da matéria do Diário, sua virtude, diz Lúcio, está em mostrar que "os Maiorana tratam de fraude de incentivos fiscais como raposa falaria de galinheiro". Isso porque os irmãos Romulo e Ronaldo também estariam envolvidos em suspeitas de irregularidades na Sudam, o primeiro com o hotel no Amazonas e o segundo, com uma fábrica de refrigerantes em Ananindeua, na região metropolitana de Belém. 
Moral da história: os dois lados têm razão quando se acusam. Mas não quando se defendem. Isto quando chegam a se defender, o que raramente fazem. Parecem partilhar o entendimento de que a melhor defesa é o ataque. Ao outro, claro. Só por esse motivo, um efeito positivo de suas brigas é fornecer à opinião pública informações que dela sonegam quando estão em calmaria (PINTO, 2005, p. 2).

As análises feitas por Lúcio ganham relevância por serem únicas, considerando-se que ninguém se ocupou tanto dos acontecimentos recentes no campo da imprensa paraense como o editor do JP. Ao mesmo tempo, devem ser valorizadas pela contextualização que oferecem, à medida que desfazem as tramas urdidas entre grupos políticos e empresas jornalísticas visando à conquista da opinião pública em nome de interesses privados.

\section{CONSIDERAÇÕES FINAIS}

Lúcio Flávio Pinto consolida no Jornal Pessoal a condição de intelectual público, certamente um dos mais ativos de sua época, no Pará. Trata-se, portanto, de um sujeito social caracterizado por um "espírito incorrigivelmente independente que não responde a ninguém", comprometido com um "mundo público" e "uma linguagem pública", como definiu Jacoby (1990, p. 249).

Desvencilhando-se dos constrangimentos organizacionais impostos pela grande imprensa, o editor do JP manteve-se no mesmo campo de atuação, o jornalismo, onde migrou paulatinamente da condição de mediador para a condição de fonte de informação. E o fez por diferentes vias: a compulsão pela leitura, a disposição para estudar e colecionar documentos, o conhecimento obtido em viagens pelos recônditos da Amazônia e pelo exterior, a formação de sociólogo, o exercício diário da reportagem, a estreita convivência com especialistas dos mais diferentes campos da política, economia, ciência e tecnologia. Mas o fez, principalmente, por entender o jornalismo como uma missão social, embutida em cada experiência do cotidiano.

Como instrumento de uma conduta intelectual, porém, o Jornal Pessoal pressupõe a responsabilidade de seu editor no encaminhamento das questões que apresenta ao debate, o que sugere exposição a toda sorte de incompreensões.
Neste aspecto, a admissão do contraditório por meio da reprodução das cartas dos leitores, na íntegra, é uma das virtudes do jornal. Esse tipo de prática prestigia o direito à informação, ainda que não seja da natureza de Lúcio Flávio fraquear ao contraditor a última palavra no debate.

Quanto à permanência do jornal no formato impresso, em um tempo no qual a proliferação de blogs e sites jornalísticos sinaliza para outras possibilidades de veiculação do conteúdo, o que Lúcio certamente rejeita é a ideia de "imaterialidade". A existência física do periódico é o atestado de sua identidade, comprometida com a constituição de uma memória da realidade regional. Por esse motivo, e não sem razão, o jornalista alimenta a certeza conformada de que o JP serve menos ao presente do que às gerações futuras.

Aos poucos, porém, o Jornal Pessoal chega à internet. Em julho de 2008 foi inaugurado o site www.jornalpessoal.com.br, que abriga as edições quinzenais do JP. A intenção, segundo Lúcio Flávio Pinto, é disponibilizar o acervo completo. Todas as edições do JP, desde o número 1 , foram digitalizadas por Angelim Pinto, filho do jornalista. No site de relacionamentos Orkut também podem ser encontradas comunidades dedicadas ao jornalista e a seu alternativo.

A inexistência de financiamento publicitário, aliada ao fato de ser produzido por uma só pessoa, de atuar na defesa de causas e de ser uma fonte de incômodos ao poder dominante, são traços que permitem associar o JP a um tipo de imprensa político-literária, desaparecida após a transformação do jornalismo em atividade empresarial. Seu objetivo não é o lucro, mas o exercício do pensamento crítico, materializado na capacidade argumentativa e na análise dos fatos em sua complexidade. É o que se nota, por exemplo, nas reflexões sobre jornalismo e política, que visam instruir o leitor para os acordos entre jornais e grupos partidários. Obviamente, as condições históricas limitam o exercício da comparação. $\mathrm{O}$ que se defende, aqui, é a similaridade na prática.

As considerações apresentadas acima fortalecem o entendimento de que o Jornal Pessoal é, de fato, uma experiência de imprensa contrahegemônica, que atua em oposição aos grupos dominantes, dos quais fazem parte as corporações de mídia. No Pará, essas corporações se nutrem na relação promíscua com os grupos políticos que se alternam na administração pública. 
Ao trazer para a agenda do cidadão os assuntos que considera mais relevantes, o JP organiza uma outra história do Pará e da Amazônia, a partir de um ângulo que não está contemplado nos grandes jornais locais. Mas não faz sentido esperar que a grande imprensa se proponha a debater, a fundo, os problemas da região. Porque o debate aberto, franco, aprofundado, levaria, naturalmente, à exposição de mazelas que a indústria midiática necessita ocultar em nome da ânsia de lucro. Não por coincidência, 18 dos 33 processos judiciais movidos até 2008 contra o editor do Jornal Pessoal são de autoria da família Maiorana, que detém um dos maiores grupos de comunicação do Norte e Nordeste do Brasil, e cujo papel nas tramas políticas está decifrado no quinzenário de Lúcio Flávio Pinto.

Sob pressão das ações judiciais, Lúcio Flávio tem merecido uma série de manifestações de apoio, no Brasil e no exterior. Em julho de 2007, recebeu da Sociedade Brasileira para o Progresso da Ciência (SBPC) uma homenagem por ocasião da abertura de $59^{a}$ reunião anual da entidade, em Belém. Foi a primeira honraria do tipo concedida pela mais importante entidade científica da América Latina a um jornalista, mas nenhum dos jornais diários do Estado fez menção ao assunto. Em outubro de 2005, foi laureado com o Prêmio Internacional de Liberdade de Imprensa, do Comitê de Proteção aos Jornalistas, por enfrentar ameaças e punições em função do trabalho que desenvolve.

O empenho em auscultar o jogo silencioso do poder é um dos maiores contributos do JP à sociedade. Essa constatação reforça a importância da presença do periódico na esfera pública paraense. Como canal de comunicação contrahegemônico, há duas décadas o Jornal Pessoal vem possibilitando a uma audiência ainda que mínima, mas qualificada, a compreensão dos desafios que se impõem ao Estado e à região. Daí a disposição desta pesquisadora em trazer à luz a história do periódico e, por conseguinte, de seu editor.

A expectativa, em suma, é a de que este estudo contribua para demonstrar que em um mundo tomado por "cercas", segundo a metáfora de Naomi Klein (2003), existem "janelas" de onde é possível lançar um outro olhar, mais humano e solidário, às causas universais.

\section{REFERÊNCIAS}

ADORNO, T. W. A indústria cultural. In: COHN, G. Comunicação e indústria cultural. São Paulo: Nacional, 1975. p. 287-295.

ASSIS, D. Acadêmico analisa mídia de olho na rua. Brasil Online, 6 set. 2003. Disponível em: $<$ http:// noticias.bol.com.br/variedades/2003/09/06/ ult90u36537.htm>. Acesso em: 10 set. 2003.

BALDELLI, P. Informazione e controinformazione. Milão: Mazzota, 1972.

BORIN, J. A notícia e suas versões, no espaço e no tempo dos grupos de pressão: de rabo preso com a classe dominante. 1987. 221 f. Tese (Doutorado em Ciências da Comunicação) - Escola de Comunicações e Artes da Universidade de São Paulo, São Paulo, 1987.

DOWNING, J. D. H. Mídia radical: rebeldia nas comunicações e movimentos sociais. São Paulo: Ed. do Senac São Paulo, 2002.

FADUL, A. M. Hegemonia e contra-informação: por uma nova práxis da comunicação. In: LINS DA SILVA, C. E. Comunicação, hegemonia e contra-informação. São Paulo: Cortez; Intercom, 1982. p. 25-39.

FONTCUBERTA, M. de; MOMPART, J. L. G. Alternativas en comunicación. Barcelona: Mitre, 1983.

JACOBY, R. Os últimos intelectuais: a cultura americana na era da academia. São Paulo: Ed. da EDUSP, 1990.

KLEIN, N. Cercas e janelas: na linha de frente do debate sobre globalização. Rio de Janeiro: Record, 2003.

KUCINSKI, B. Jornalistas e revolucionários: nos tempos da imprensa alternativa. São Paulo: Scritta, 1991.

LIMA, V. A. Mídia: teoria e política. São Paulo: Fundação Perseu Abramo, 2001.

LINS DA SILVA, C. E. Comunicação, hegemonia e contra-informação. São Paulo: Cortez; Intercom, 1982. 
MC BRIDE, S. Um mundo e muitas vozes: comunicação e informação na nossa época. Rio de Janeiro: Fundação Getúlio Vargas, 1983.

ORLANDI, E. As formas do silêncio: no movimento dos sentidos. Campinas: Ed. da Unicamp, 1995.

O'Sullivan, T. et al. Conceitos-chave em estudos de comunicação e cultura. Piracicaba: Unimep, 2001.

PINTO, L. F. O novo imperador. Jornal Pessoal, Belém, ano III, n. 55, p. 1-2, jan. 1990.

Imprensa: a guerra de cifrões. Jornal Pessoal, Belém, ano IV, n. 70, p. 1-3, jul. 1991.

Lúcio Flávio Pinto. 5 maio 2004 e 18 jul. 2005 (gravada). Entrevistas concedidas à Maria do Socorro Furtado Veloso.

Elite: guerra vai continuar? Jornal Pessoal, Belém, ano XVIII, n. 341, p. 1-2, mar. 2005.

SODRÉ, N. W. História da imprensa no Brasil. Rio de Janeiro: Mauad, 1999.

Recebido: 28/03/2009

Received: 03/28/2009

Aprovado: 21/04/2009

Approved: 04/21/2009

Revisado: 30/10/2009

Reviewed: 10/30/2009 